\title{
Warping Effect to Bend-twist Coupling Characteristics for Box Spar of Wind Turbine Blade
}

\author{
Xing-Yin ZHOU ${ }^{1, a}$, Li-Qiang AN ${ }^{1, b}$, Zhang-Qi WANG ${ }^{1, c}$ \\ ${ }^{1}$ School of Energy, Power and Mechanical Engineering, North China Electric Power University, \\ Baoding, Hebei 071003, China \\ axy_zhou@163.com, balq2146@163.com, cwangzq2093@163.com
}

Keywords: Bend-twist Coupling, Warping Effects, Sectional Stiffness, Beam Model.

\begin{abstract}
In order to study the effects of sectional warping to bend-twist coupling characteristics for box spar of wind turbine blade, section stiffness of different regions are calculated with weather considering warping effect or not, the results show that warping effects differently in different part of the blade and the length width ratio and thickness of spar cap are two factors that determine impact degree of warping. Section stiffness of a 5MW blade box spar considering warping effect are calculated, bend-twist coupling coefficients are got. The results show that warping effect bend-twist coupling coefficient of box spar greatly and it should be considered when research the blade bend-twist coupling.
\end{abstract}

\section{Introduction}

With higher specific strength and specific modulus, composite material becomes popular in wind turbine blades. Furthermore, the blade exhibits twisting when it subjects a pure bending load due to the anisotropy of the composite materials. In reference $[1,2,3]$, the results show that the enough twist-bend coupling can reduce $10 \%$ of the fatigue load.

The spar is main component in wind turbine blade and influences the bearing behavior of blade. Box spar that consists of spar cap and shear web is one of common types in spars. Length of large modern blades are exceed 100 meter, dimension and ply of spar vary from blade root to blade tip. The maximum ply thickness of spar cap can reach almost $140 \mathrm{~mm}$ [4] and cross sections do not satisfy the plane hypothesis. So it is necessary to consider warping effect of sections.

The box spar of a 5MW blade is researched in this paper. Stiffness of different sections are calculated respectively with classical lamination plate theory which not considering warping effect and theory which considering warping effect. On this basis, the warping effect to bend-twist coupling of the spar is further discussed.

\section{The Formula of the Bend- twist Coupling}

Static equivalence of the wall stresses with the cross-sectional stress resultants produces the following equations relating the bending moment, $M$, and torsion, $T$, to the bending curvature $K_{x}$, and rate of twist $\varphi_{z}[5]$ :

$$
\left\{\begin{array}{c}
M \\
T
\end{array}\right\}=\left[\begin{array}{cc}
E I & -g \\
-g & G J
\end{array}\right]\left\{\begin{array}{c}
K_{x} \\
\phi_{z}
\end{array}\right\} .
$$

where, $E I$ is the bending stiffness, $G J$ is the torsional stiffness, and $g$ is the coupling stiffness. Then, $\alpha$ is defined as a parameter used to descript the level of bend- twist coupling,

$$
\alpha=\frac{g}{\sqrt{E I G J}} .
$$


It can be seen from Eq. 2 that sectional stiffness must be calculated before bend- twist coupling is research.

\section{Beam model of Box Spar}

The procedure of box spar beam model establishing based on 3D finite element models is showed in Fig.1, where $X Y Z$ is box spar coordinate system, $X$ is the edgewise direction which lies in the rotation plane; $Y$ is the flapwise direction which perpendicular to the rotation plane; $Z$ is the pitch axis, $Y Z$ plane is parallel to the web plane. Perpendicular to the pitch shaft, the box spar is divided into many segments. Each segment can be treated as a beam element.

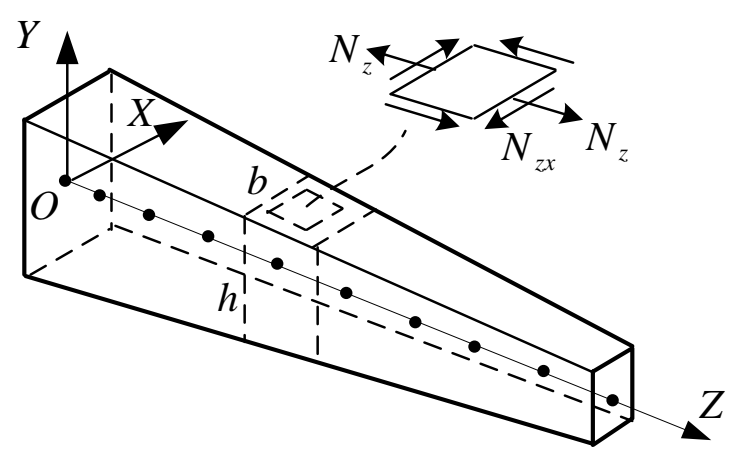

Fig. 1 Beam model of a box spar

Beam Model Based on Classical Laminate Theory. Constitutive equations for an anisotropic material can be written as

$$
\left\{\begin{array}{l}
N_{z} \\
N_{x} \\
N_{z x}
\end{array}\right\}=\left[\begin{array}{lll}
A_{11} & A_{12} & A_{16} \\
A_{12} & A_{22} & A_{26} \\
A_{16} & A_{26} & A_{66}
\end{array}\right]\left\{\begin{array}{l}
\varepsilon_{z} \\
\varepsilon_{x} \\
\gamma_{z x}
\end{array}\right\} .
$$

where, the quantities $A_{i j}$ are stiffness coefficients specified for laminated composite wall construction, as given in conference [6]. $\varepsilon_{z}$ and $\varepsilon_{x}$ are axial and contour normal strains, respectively; $\gamma_{z x}$ is the shear strain.

Assuming that $N_{x}=0$ and we can got

$$
\left\{\begin{array}{c}
N_{Z} \\
N_{Z X}
\end{array}\right\}=\left[\begin{array}{ll}
K_{11} & K_{12} \\
K_{12} & K_{22}
\end{array}\right]\left\{\begin{array}{c}
\varepsilon_{Z} \\
\gamma_{Z X}
\end{array}\right\} \text {. }
$$

where,

$$
K_{11}=A_{11}-\frac{A_{12}^{2}}{A_{22}}, K_{12}=A_{16}-\frac{A_{12} A_{26}}{A_{22}}, K_{22}=A_{66}-\frac{A_{26}^{2}}{A_{22}}
$$

By the definition of torsional moment and bending moment, [7]

$$
\begin{aligned}
& T=2 N_{z x}^{c a p} b\left(\frac{h}{2}\right)+2 N_{z x}^{w e b} h\left(\frac{b}{2}\right) \\
& M=2 N_{z}^{c a p} b h+\frac{1}{6} A_{11}^{w e b} h^{3} \kappa_{x}
\end{aligned}
$$


Substituting Eq.3 and 4 into Eq.5, we got bending stiffness EI, torsional stiffness $G J$ and coupling stiffness $g$,

$$
\begin{aligned}
& E I=\frac{1}{2} b h^{2} K_{11}+\frac{1}{6} h^{3} A_{11}^{w e b} \\
& G J=\frac{1}{2} b h^{2} K_{22}+\frac{1}{2} b^{2} h A_{66}^{w e b} . \\
& g=\frac{1}{2} b h^{2} K_{12}
\end{aligned}
$$

Beam Model Considering Warping Effect. The displacement at a point of the cross section is defined as

$$
s=\Lambda r+N u
$$

where, $\boldsymbol{r}$ is the displacement of the cross section reference point, that is, the nodes of beam element under the box spar coordinate system. $\boldsymbol{u}$ is node displacement of the section 2D finite element, which is used to described nodal warping displacement. $N$ is the finite element shape functions used to describe warping. $\boldsymbol{\Lambda}$ is coordinates matrix,

$$
\boldsymbol{\Lambda}=\left[\begin{array}{cccccc}
1 & 0 & 0 & 0 & 0 & -y \\
0 & 1 & 0 & 0 & 0 & x \\
0 & 0 & 1 & y & -x & 0
\end{array}\right] .
$$

With the definition of strain, the strain at a point of the cross section can be expressed as

$$
\boldsymbol{\varepsilon}=\boldsymbol{H} \Lambda \psi+\Gamma \boldsymbol{N u}+\boldsymbol{H} N \frac{\partial u}{\partial \mathrm{z}}
$$

where,

$$
\boldsymbol{H}=\left[\begin{array}{lll}
0 & 0 & 0 \\
0 & 0 & 0 \\
0 & 0 & 0 \\
1 & 0 & 0 \\
0 & 1 & 0 \\
0 & 0 & 1
\end{array}\right], \quad \boldsymbol{\Gamma}^{T}=\left[\begin{array}{cccccc}
\frac{\partial}{\partial x} & 0 & \frac{\partial}{\partial y} & 0 & 0 & 0 \\
0 & \frac{\partial}{\partial y} & \frac{\partial}{\partial x} & 0 & 0 & 0 \\
0 & 0 & 0 & \frac{\partial}{\partial x} & \frac{\partial}{\partial y} & 0
\end{array}\right] .
$$

According to virtual work principle, equilibrium equations of cross section is defined as [8]:

$$
\begin{aligned}
\boldsymbol{G} \frac{\partial^{2} \boldsymbol{u}}{\partial z^{2}}+\left(\boldsymbol{C}-\boldsymbol{C}^{T}\right) \frac{\partial \boldsymbol{u}}{\partial z}+\boldsymbol{L} \frac{\partial \boldsymbol{\psi}}{\partial z}-\boldsymbol{E} \boldsymbol{u}-\boldsymbol{R} \boldsymbol{\psi} & =0 \\
\boldsymbol{I}^{T} \frac{\partial \boldsymbol{u}}{\partial z}+\boldsymbol{R}^{T} \boldsymbol{u}+\boldsymbol{I} \boldsymbol{\psi} & =\boldsymbol{\theta} \\
\frac{\partial \boldsymbol{\theta}}{\partial z} & =\boldsymbol{T}_{r}^{T} \boldsymbol{\theta}
\end{aligned}
$$

where, $\boldsymbol{\theta}$ is internal force in the cross section, as shown in Fig. 2. $\boldsymbol{\theta}=\left[\begin{array}{llllll}T_{x} & T_{y} & T_{z} & M_{x} & M_{y} & M_{z}\end{array}\right]^{T}$, where, $T_{x}, T_{y}$ are shear forces, $T_{z}$ is axial force; $M_{x}, M_{y}$ are 
bending moments, $M_{z}$ is torsional moment ; $\boldsymbol{\psi}$ represent deformation of the beam, $\boldsymbol{\psi}=\left[\begin{array}{llllll}\tau_{x} & \tau_{y} & \tau_{z} & \kappa_{x} & \kappa_{y} & \kappa_{z}\end{array}\right]^{T}$, where, $\tau_{x}$ and $\tau_{y}$ represent shear strains; $\tau_{z}$ is the axial strain; $\kappa_{x}$, $\kappa_{y}$ are the curvatures around $\mathrm{x}$ and y respectively, $\kappa_{z}$ is the torsion curvatures. $\boldsymbol{G}, \boldsymbol{C}, \boldsymbol{L}, \boldsymbol{E}, \boldsymbol{R}, \boldsymbol{I}$ and $\boldsymbol{T}_{r}$ are coefficient matrixes.

$$
\begin{aligned}
\boldsymbol{T}_{r} & =\left[\begin{array}{llllll}
0 & 0 & 0 & 0 & -1 & 0 \\
0 & 0 & 0 & 1 & 0 & 0 \\
0 & 0 & 0 & 0 & 0 & 0 \\
0 & 0 & 0 & 0 & 0 & 0 \\
0 & 0 & 0 & 0 & 0 & 0 \\
0 & 0 & 0 & 0 & 0 & 0
\end{array}\right], \boldsymbol{G}=\int_{A} \boldsymbol{N}^{\mathrm{T}} \boldsymbol{H}^{\mathrm{T}} \boldsymbol{Q} \boldsymbol{H} \boldsymbol{N} d A \quad \boldsymbol{C}=\int_{A} \boldsymbol{N}^{\mathrm{T}} \boldsymbol{H}^{\mathrm{T}} \boldsymbol{Q} \boldsymbol{\Gamma} \boldsymbol{N} d A, \boldsymbol{L}=\int_{A} \boldsymbol{N}^{\mathrm{T}} \boldsymbol{H}^{\mathrm{T}} \boldsymbol{Q H} \boldsymbol{H} d A, \\
\boldsymbol{E} & =\int_{A}^{\boldsymbol{N}^{\mathrm{T}} \boldsymbol{\Gamma}^{\mathrm{T}} \boldsymbol{Q} \boldsymbol{\Gamma} \boldsymbol{N} d A \boldsymbol{R}}, \boldsymbol{R}=\int_{A} \boldsymbol{N}^{\mathrm{T}} \boldsymbol{\Gamma}^{\mathrm{T}} \boldsymbol{Q H} \boldsymbol{\Lambda} d A \quad \boldsymbol{I}=\int_{A} \boldsymbol{\Lambda}^{\mathrm{T}} \boldsymbol{H}^{\mathrm{T}} \boldsymbol{Q H} \boldsymbol{\Lambda} d A .
\end{aligned}
$$

where, $Q$ is the material constitutive matrix.

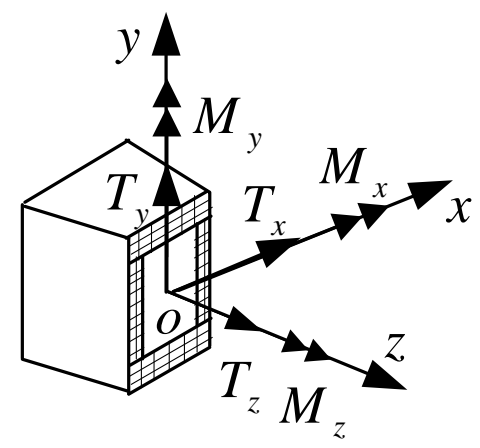

(a) Internal force

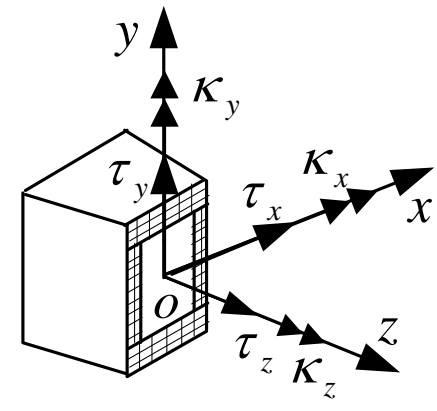

(b) Strain

Fig. 2 Coordination, internal force and strain of section

Solving the Eq. 9 and using the virtual work principle, the cross section compliance matrix can be computed as ${ }^{[8]}$

$$
\boldsymbol{F}_{s}=\left[\begin{array}{c}
\frac{\partial \boldsymbol{P}}{\partial z} \\
\boldsymbol{P} \\
\boldsymbol{V}
\end{array}\right]^{T}\left[\begin{array}{ccc}
\boldsymbol{G} & \boldsymbol{C} & \boldsymbol{L} \\
\boldsymbol{C}^{T} & \boldsymbol{E} & \boldsymbol{R} \\
\boldsymbol{L}^{T} & \boldsymbol{R}^{T} & \boldsymbol{I}
\end{array}\right]\left[\begin{array}{c}
\frac{\partial \boldsymbol{P}}{\partial z} \\
\boldsymbol{P} \\
\boldsymbol{V}
\end{array}\right]
$$

where, $\boldsymbol{P}$ and $\boldsymbol{V}$ are coefficient matrixes. Then, stiffness matrix can be expressed as

$$
\boldsymbol{K}_{s}=\boldsymbol{F}_{s}^{-1}=\left[\begin{array}{llllll}
K_{11} & K_{12} & K_{13} & K_{14} & K_{15} & K_{16} \\
K_{21} & K_{22} & K_{23} & K_{24} & K_{25} & K_{26} \\
K_{31} & K_{32} & K_{33} & K_{34} & K_{35} & K_{36} \\
K_{41} & K_{42} & K_{43} & K_{44} & K_{45} & K_{46} \\
K_{51} & K_{52} & K_{53} & K_{54} & K_{55} & K_{56} \\
K_{61} & K_{62} & K_{63} & K_{64} & K_{65} & K_{66}
\end{array}\right] .
$$

where, $K_{44}$ is the flapwise bending stiffness, $K_{66}$ is the torsional stiffness, $K_{46}$ is the coupling stiffness. 


\section{Twist-bend Coupling Properties of Box Spar}

Model Parameters. A schematic of a box spar is depicted in Fig. 3, where the box spar composed of spar caps and webs, "H" refers to the height of a box spar, " $t$ " refers to the thickness of a box spar. The spar cap is made up of uni-directional FRP with $0^{0}$ ply orientation and shear webs are sandwich construction with $50 \mathrm{~mm}$ foam between $3 \mathrm{~mm}$ double bias material on the outer surfaces. The width of the box spar is $0.75 \mathrm{~m}$. Table 1 describes the breakdown of material usage in the box spar.

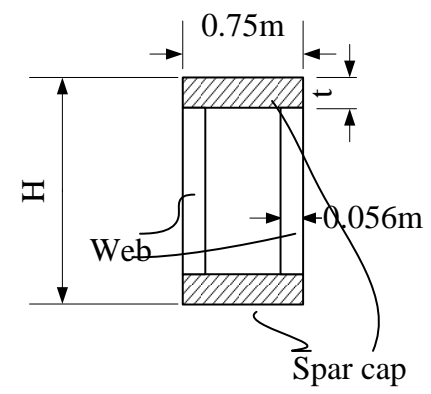

Fig. 3 Box spar

Tab. 1 Layer material properties

\begin{tabular}{l|l|l|l|l}
\hline Material & $\mathrm{E}_{1}[\mathrm{GPa}]$ & $\mathrm{E}_{2}[\mathrm{GPa}]$ & $\mathrm{G}_{12}[\mathrm{GPa}]$ & $v_{12}$ \\
\hline uni-directional FRP & 38.887 & 9.0 & 3.6 & 0.249 \\
\hline double-bias FRP & 11.7 & 11.7 & 9.77 & 0.501 \\
\hline foam & 0.256 & 0.256 & 0.022 & 0.3 \\
\hline
\end{tabular}

Three box spars with different dimensions are selected from a 5MW blade ${ }^{[9]}$, and are marked as model A, B and C respectively . Model A locates in the maximum chord station where the thickness of the spar cap is the maximum, model B locates in transition region of blade root, model C locates in pneumatic region, the dimensions of three models are list in Table 2.

Tab. 2 Dimensions of spar cap at different section

\begin{tabular}{l|l|l|l}
\hline & $\mathrm{H}[\mathrm{m}]$ & $\mathrm{t}[\mathrm{m}]$ & location \\
\hline model A & 1.5 & 0.0846 & the maximum chord station \\
\hline model B & 2.5 & 0.0376 & transition region \\
\hline model C & 0.8 & 0.060 & pneumatic region \\
\hline
\end{tabular}

Stiffness Calculation of Three Models. The sectional stiffness of three models are calculated respectively with classical lamination plate theory which not considering warping effect and theory which considering warping effect. The results are listed in Table 3.

Tab. 3 Stiffness of box spar at different section

\begin{tabular}{c|c|c|c|c}
\hline & \multicolumn{2}{|c|}{ no warping effect } & \multicolumn{2}{c}{ warping effect } \\
\cline { 2 - 5 } & $\mathrm{EI}\left[10^{9} \mathrm{Nm}^{2}\right]$ & $\begin{array}{l}\mathrm{GJ}\left[10^{9} \mathrm{Nm}^{2}\right. \\
]\end{array}$ & $\mathrm{EI}\left[10^{9} \mathrm{Nm}^{2}\right]$ & $\begin{array}{l}\mathrm{GJ}\left[10^{9} \mathrm{Nm}^{2}\right. \\
]\end{array}$ \\
\hline model A & 2.51 & 0.079 & 2.23 & 0.074 \\
\hline model B & 3.52 & 0.128 & 3.49 & 0.121 \\
\hline model C & 0.485 & 0.036 & 0.412 & 0.035 \\
\hline
\end{tabular}

The bending stiffness $E I$ and torsional stiffness $G J$, as seen in Table 3, decreases with considering warping effect which include in-plane and out-of-plane warping. Taking the results considering warping effect as a benchmark, define the deviation between stiffness of the two methods as 
deviation $=\frac{K_{W}-K}{K_{W}} \times 100 \%$

where, $K_{W}$ is the stiffness considering warping effect, $K$ is the stiffness without considering warping effect.

The deviation between CLT and warping effect are shown in Fig. 4.

EI

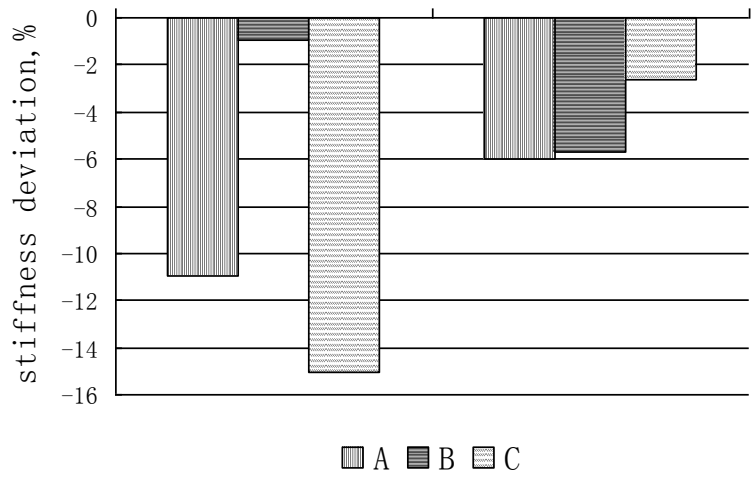

Fig. 4 Deviation of sectional stiffness

As shown in Fig. 4, the difference between two methods is large in model A and C. Also, we found that the difference between the two methods of model B is small, that is the warping effect can be ignored. The reason is that the spar cap thickness of model B is small and the height of spar is large. That is, length width ratio and thickness of spar cap are two factors that affect the results.

\section{Bend-twist Coupling Analysis for Box Spar of a 5MW Blade.}

The spar cap of the 5MW blade[9] is simplified to a box spar which spar cap is vertical to shear web and the length width ratio and thickness of spar cap very from blade root to blade tip. The section is shown in Fig. 3 and material usage in the box spar is list in Table 2. The box spar model of the 5MW blade is shown in Fig. 5 C.H. Ong and S.W. Tsai [10] suggested that the optimal fiber orientation angle to produce maximum bend-twist coupling is approximately $20^{\circ}$. In order to appear maximum bend-twist coupling in the 5MW blade, the uni-directional FRP of spar cap are plied at $20^{\circ}$. The coupling coefficient of the spar is shown in Fig. 6.

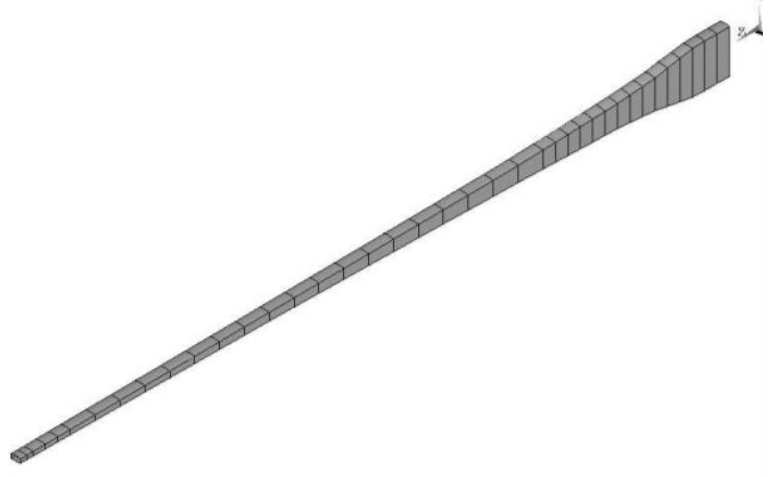

Fig.5 Box spar of a 5MW wind turbine blade

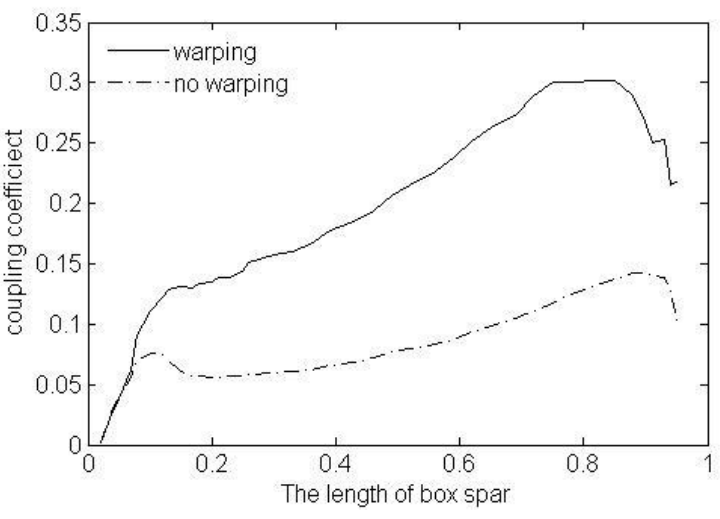

Fig.6 Coupling coefficient of the box spar

As shown in Fig. 6, we found that warping increases the bend-twist coupling coefficient. The changes in the coupling coefficient come from the reduction in bending stiffness $E I$ and torsional stiffness $G J$. Furthermore, we found that the variation tendency of coupling coefficients is same with reference [9]. This is also shown that spar as a main component in blade effect the deformation 
behavior of blade and the bend-twist coupling characteristics of spar determine the bend-twist coupling characteristics of blade.

\section{Conclusions}

In this paper, the stiffness of different sections of a 5MW blade spar cap are calculated with considering warping or not and bend-twisting coupling of the 5MW blade spar cap is calculated. The following conclusions are drawn.

(1) Warping effects differently in different parts of the blade and has a great effect in the maximum chord station and airfoils region. The length width ratio and thickness of spar cap are two factors that determine impact degree of warping effect.

(2) Warping effects bend-twist coupling coefficient of box spar greatly and it should be considered when research bend-twist coupling characteristics of blades.

(3) Bend-twist coupling characteristics of spar determine the bend-twist coupling characteristics of blade. The design of bend-twist coupling characteristics of blade can be achieved through designing the bend-twist coupling characteristics of spar.

\section{Acknowledgements}

This research was supported by the Fundamental Research Funds for the Central Universities (13MS82, 2014ZD33) and Hebei Province Natural Science Foundation (E2013502291).

\section{References}

[1]D.W. Lobitz, D.J. Laino: 1999 ASME Wind Energy Symposium, 18th, Aerospace Sciences Meeting and Exhibit, 37th (Reno, NV, January 11-14,1999). p.125.

[2]D.W. Lobitz, P. Veers and D.J. Laino: 2000 ASME Wind Energy Symposium, 19th, Aerospace Sciences Meeting and Exhibit, 38th (Reno, NV, January 10-13, 2000). p.405.

[3]D.W. Lobitz, P.S. Veers, G.R. Eisler, D.J. Laino, P.G. Migliore and G. Bir: The Use of Twist-Coupled Blades to Enhance the Performance of Horizontal Axis Wind Turbines, Report SAND2001-1003, Sandia National Laboratories, Albuquerque, NM, (2001).

[4]D. Todd Griffith, Brian R. Resor: Description of Model Data for SNL100-00: The Sandia 100-meter All-glass Baseline Wind Turbine Blade, Report SAND2011-3779, Sandia National Laboratories, Albuquerque, NM ,(2011).p.40

[5]J. Locke, Ulyses Valencia: Design Studies For Twist-Coupled Wind Turbine Blades, Report SAND2004-0522, Sandia National Laboratories, (2004).

[6]Shen Guanlin, Hu Gengkai. Mechanics of Composite Material. Beijing: tsinghua university press,(2012)

[7]Zhang guijiang: Optimal Design Techniques Study with the Elastic Tailoring Application of the Aircraft composite Structure. Xi'an: Northwestern Polytechnical University, 2006.

[8]Blasques J. P. : Optimal design of laminated composite beams. Kgs. Lyngby: Technical University of Denmark, 2011.

[9] Zhou Xingyin, An Liqiang, Wang Zhangqi. RENEWABLE ENERGY RESOURCES. Vol. 33(2015),p.238-243

[10]C.H. Ong, S.W. Tsai: Design, Manufacture and Testing of a Bend-Twist D-Spar, Report SAND99-1324, Sandia National Laboratories, Albuquerque, NM, (1999). 